\title{
Pres-FINAL-2009: Pediatric rheumatology practitioners experience with biologics in juvenile dermatomyositis: survey results
}

\author{
A Patwardhan ${ }^{1,2^{*}}$, K Rouster-Stevens $^{3}$, C Spencer $^{2}$, CARRA-Childhood Arthritis Research Alliance \\ From 20th Pediatric Rheumatology European Society (PReS) Congress \\ Ljubljana, Slovenia. 25-29 September 2013
}

\begin{abstract}
Introduction
Biologic therapy is increasingly prescribed in rheumatologic disorders. Juvenile dermatomyositis (JDM), the most common inflammatory myopathy in children, can be challenging to manage in a subset of patients. There are multiple reports of cytokine involvement in JDM. There is a paucity of information regarding the use of biologics for JDM among pediatric rheumatology practitioners, and only one clinical trial investigating a biologic in JDM.
\end{abstract}

\section{Objectives}

The purpose of the study is to examine pediatric rheumatology (PR) experience in North America and Canada with biologic therapy in children with JDM.

\section{Methods}

The Childhood Arthritis and Rheumatology Research Alliance JDM Subcommittee on Biologics developed a 15-question on-line survey. Of the 231 pediatric rheumatology practitioners contacted, 105 (45\%) participated between $2 / 17-3 / 20 / 2012$.

\section{Results}

Over half $(57 \%)$ of the respondents currently managed 1-10 patients with JDM; $10 \%$ of respondents reported $\geq 20$ patients with JDM in their practice. Sixty-one percent of respondents had used biologics in patients with JDM, with $32 \%, 5 \%$, and $4 \%$ prescribing rituximab, etanercept and infliximab, respectively; $17 \%$ had prescribed more than one biologic. The majority of respondents $(89 \%)$ had used biologics in combination with other

'Pediatric Rheumatology, University of Misouri School of Medicine, Columbia, MO, USA

Full list of author information is available at the end of the article therapies, while $11 \%$ had used biologics as monotherapy in JDM. The biologics used by the respondents were, rituximab, infliximab, etanercept and anakinra and abatacept. Among the respondents that used biologics, uncontrolled disease was the primary rationale for prescribing this medication. Over half of respondents used biologics after the patients failed other therapies; $11 \%$ of respondents used biologics for systemic (internal organ) involvement and $15 \%$ had used biologics for severe ulcerative disease. Seventy-three percent of respondents that used biologics noted improvement, while 10\% reported worsening disease. Over half (53\%) of respondents that used biologics noted improvement in calcinosis, while $64 \%$ reported side effects (common and uncommon). Among the respondents that had not used biologics (39\%) in JDM, 88\% would use this therapy if the opportunity arose; nearly half $(47 \%)$ of these respondents had not used biologics because of uncertainty regarding effectiveness in JDM. Seventy percent of practitioners recommended that biologics be formally studied in patients with JDM; $24 \%$ of respondents were unsure and $6 \%$ felt biologics should not be studied in patients with JDM.

\section{Conclusion}

Several PR have used biologics in the management of pediatric patients with JDM. Among respondants that have not used biologics in this patient population, most would be interested in prescribing biologics. This survey supports the rationale for considering clinical trials and consensus protocols to elucidate the safety and effectiveness of biologics in children with JDM. Further information will be gathered by the CARRA JDM Subcommittee on Biologics through second survey to prioritize specific medications for investigation. 


\section{Disclosure of interest}

None declared.

\section{Authors' details}

${ }^{1}$ Pediatric Rheumatology, University of Misouri School of Medicine, Columbia

MO, USA. Pediatric Rheumatology, Ohio State University, Columbus, $\mathrm{OH}$,

USA. ${ }^{3}$ Pediatric Rheumatology, University of Emroy, Atlanta, USA.

Published: 5 December 2013

doi:10.1186/1546-0096-11-S2-P22

Cite this article as: Patwardhan et al.: Pres-FINAL-2009: Pediatric

rheumatology practitioners experience with biologics in

juvenile dermatomyositis: survey results. Pediatric Rheumatology 201311

(Suppl 2):P22

Submit your next manuscript to BioMed Central and take full advantage of:

- Convenient online submission

- Thorough peer review

- No space constraints or color figure charges

- Immediate publication on acceptance

- Inclusion in PubMed, CAS, Scopus and Google Scholar

- Research which is freely available for redistribution

Submit your manuscript at www.biomedcentral.com/submit
C Biomed Central 